\title{
PERCEPTIONS OF REHABILITATIVE CHANGE AMONG INCARCERATED PERSONS ENROLLED IN A PRISON-EQUINE PROGRAM (PEP)
}

\author{
Joyce A. Arditti, Ph.D. ${ }^{1}$ \\ Amy A. Morgan, M.S., LMFT \\ Sara Spiers, M.P.A. \\ Virginia Buechner-Maxwell, DVM \\ Virginia Tech \\ Vicky Shivy, Ph.D. \\ Virginia Commonwealth University
}

\begin{abstract}
Guided by a grounded theory methodology, the authors propose a theory of rehabilitation for incarcerated persons within a prison equine program (PEP). Interviews with ten incarcerated men yielded a grounded theory of rehabilitative change centered around the importance of relationships with program staff and horses, and the uniqueness of the barn-equine environment in promoting safe attachments and positive views of self. Special emphasis is placed on the development of secure reparative attachments between men and their horses grounded in acceptance and mutual empathy, as well as the development of redemptive identities whereby participants viewed themselves as having purpose and value as human beings. Implications for policy and practice for fostering effective rehabilitation in incarceration settings are discussed.
\end{abstract}

Keywords: Prison-Equine Programs, Prison Rehabilitation, Grounded Theory, Redemption Scripts, Reparative Attachment

\section{INTRODUCTION}

Approximately 700,000 prisoners are released from prison or jail every year (Durose, Cooper, \& Snyder, 2014). Many of these same men will return to prison, typically within three years of release (Langan \& Levin, 2002). Research has documented the multiple challenges associated with reentry, like housing and employment, along with complying with the requirements of probation or parole (Hattery \& Smith, 2010; Travis, 2005). Former prisoners' histories of disadvantage and the stigma attached to incarceration, further contribute to the difficulties they may have in making it on the "outside" (Arditti, 2012; Foster \& Hagan, 2007).

\footnotetext{
${ }^{1}$ Corresponding Author: Department of Human Development and Family Science; 311 Wallace Hall; Blacksburg, VA 24061; arditti@vt.edu; 540-231-5758. The research was funded by a grant from the College of Liberal Arts and Human Sciences at Virginia Tech. Additional support was provided by the Center for Animal Human Relationships (CENTAUR), Virginia-Maryland College of Veterinary Medicine at Virginia Tech.
} 


\section{ARDITTI ET AL.}

Given the unprecedented numbers of individuals returning to community and family life from prison, policymakers and practitioners continue to examine ways to help promote positive reintegration scenarios for formerly incarcerated persons (Visher, Lattimore, Barrick, \& Tueller, 2016).

Prison rehabilitation programs are often designed to encourage skill-building and prosocial behaviors among participants (Vernick \& Reardon, 2001). Providing incarcerated individuals with comprehensive, coordinated services during incarceration and reentry improves post-release outcomes (Visher et al., 2016). Prison-based Equine Programs (PEP) utilizes horses to rehabilitate incarcerated individuals. As of 2014, fifteen states currently have PEPs affiliated with their correctional facilities (Bachi, 2014). These programs are considered beneficial for incarcerated persons (hereafter referred to as IPs) as they integrate specific career skills along with opportunities to obtain socio-emotional benefits that are associated with the animal-human bond (Bachi, 2013; 2014). Guided by an attachment lens, prison-equine program scholars have conceptualized the rehabilitative mechanism within human-animal bonds as stemming from strong relationships (i.e., with humans and/or animals) that provide corrective attachment experiences (Bachi, 2014; Zilcha-Mano, Mikulincer, \& Shaver, 2011).

Despite the potential for prison-equine programs to promote rehabilitation, there is a dearth of empirical literature on how prison-equine programs may contribute to change for incarcerated people (Bachi, 2013; 2014). The literature that does exist is limited and often does not include the voices of incarcerated participants. Further, current literature does not explore, in depth, the underlying psychological and relational mechanisms involved in rehabilitative change during prison equine program participation (Bachi, 2014). Specifically, PEP scholars have identified a need for rigorous research that explores the nature of human-animal relationships in PEPs and how these experiences contribute to psychological change in carceral settings (Bachi, 2014). The present study seeks to address this gap in the literature by proposing a grounded theory of rehabilitative change based on the voices of incarcerated men participating in a PEP.

The present study examined incarcerated participant experiences in a PEP program (hereafter referred to as "Blue Hills," which is a pseudonym for the program) to understand how it might promote change and responses related to reintegration among incarcerated men. We seek to expand criminological theories of desistance, which center on shifts to prosocial identities and roles, to more fully consider contextual and relational transactions between PEP participants and their environments, the horses, and persons involved in the PEP. The purpose of the study was to gain the views of incarcerated participants regarding the program based on in-depth interviews. Our grand tour question guiding the study's analysis was: How do Blue Hills' participants experience change and rehabilitation within a PEP?

\section{BACKGROUND AND SIGNIFICANCE}

\section{Prison-Equine Programs}

Horses were first introduced into prison systems in the late 1970s when the Bureau of Land Management partnered with the National Organization for Wild American Horses and the state penitentiary in Canon City, Colorado to develop a horse training program for captive wild mustangs (Strimple, 2003). The Colorado program was considered one of the first of its kind, as it provided the incarcerated participants an opportunity to develop job skills while also learning how to care for another living being (Strimple, 2003). In 1982, the Thoroughbred Retirement 
Foundation (TRF) was founded and the organization formed a cooperative agreement with the Wallkill Correctional Facility in upstate New York. This agreement established one of their first retirement farms for ex-racehorses. Using learning materials provided by TRF, inmates received extensive training in all aspects of horse care and the program became accredited (Strimple, 2003). Today, 15 state correctional systems operate prison-based equine programs (PEPs) (Bachi, 2014). While a number of benefits have been described, these conclusions are based almost entirely on anecdotal assessments, rather than empirical studies (Furst, 2006).

Consequently, nearly every published review on this topic includes a call for systematic research to verify the benefits of these programs.

The Blue Hills Program is housed in a Mid-Atlantic state. It was established approximately ten years ago as a collaborative effort among the Thoroughbred Retirement Foundation (TRF) non-profit Second Chances program, and the Department of Corrections (DOC). Participants are selected from a pool of applicants and assigned to the program for six months, during which they are the main caretakers for the horses. On a daily basis, the participants are responsible for leading the horses in and out, mucking stalls, grooming, feeding, and doing round-pen work. This hands-on experience is complemented by classroom training in equine nutrition, physiology, and tack and stable management. TRF uses the Groom Elite curriculum, developed by Reid McLellan, Ph.D., which is also taught at racetracks. Graduates become certified, and the Foundation assists them, upon their release, in finding jobs in the horse industry.

Blue Hills is considered a highly successful program by all involved and this view is supported by the low rates of recidivism in graduates of the program. Anecdotal information supplied by Blue Hills suggests rates of recidivism for program participants is as low as 3-6\%, compared against $23 \%$ for the general population of the Mid-Atlantic state inmates (VADOC, 2016), and 68\% nationally (Durose et al., 2014). However, the elements of Blue Hills that contribute to perceptions of program success have not been identified, and, in general, there are few formal investigations of PEPs in the scientific literature. A primary purpose of this study was to provide an in-depth examination of participant perspectives' of the Blue Hills program utilizing systematic qualitative data collection strategies and grounded theory analysis. Such an approach permits for the development of a framework to explain the processes and influences of a PEP program to generate theory. Consistent with qualitative criminology applications that generate theory about the lives of incarcerated persons (Miller, Copes, \& Hochstetler; 2015; Hochstetler \& Copes, 2015) and the use of grounded theory to examine offender rehabilitation processes (e.g., Cantora, 2013; Smith \& Ferguson, 2005) our goal was to utilize an inductive research approach to reveal nuances about life changes and rehabilitative experiences as it pertained to participants within a PEP.

\section{Sensitizing Concepts: Spillover and Redemption Scripts}

The qualitative approach of the present study incorporated sensitizing concepts derived from extant theory within prevention science and the empirical literature on prisoner reentry and desistance. Sensitizing concepts often serve as a starting point for qualitative analysis and can loosely guide interpretation (Bowen, 2006; Charmaz, 2006). Positive spillover effects refer to beneficial changes within and across domains of functioning (Doty, Davis, \& Arditti, 2017). 


\section{ARDITTI ET AL.}

These effects may extend beyond the specific goals of a particular intervention (e.g., in the case of Blue Hills, vocational training) and stem largely from positive relational patterns (Masten \& Cicchetti, 2010). Within domain spillover, effects may include gains in inmate psychological functioning through the establishment of generative roles which afford meaning and achievement in one's life (Hlavka, Wheelock, \& Jones, 2015). Across domain, benefits may involve beneficial changes in other parts of participants' lives as well as influences on the non-target population (Angelucci \& DiMaro, 2015) such as families and communities associated with the IP.

In addition to considering the possibility of spillover, we were also interested in exploring what role program participation may have in the construction of program participants' redemption scripts (Maruna, 2001). Redemption scripts are defined as positive cognitive transformation narratives on the part of reentrants that sustain them during adversity. These scripts are theorized to be a central rehabilitative component in the desistance from crime and generally involve the reinvention of how the IP sees oneself (i.e., distancing and explanation about past criminal activities), seeing one's existence as meaningful and contributing to social institutions, and a sense of agency, or the ability to engage in voluntary actions that matter and promote "good lives" (Liem \& Richardson, 2014; Maruna, 2001). It is worth noting that transformation narratives among IPs may not necessarily relate to intentional efforts aimed at rehabilitation, but an effort to make sense out of their imprisonment, wishes for a positive future, and confidence in their ability to desist after release (Schinkel, 2015). Here we were interested in learning more about how Blue Hills participants saw themselves and their futures, as well as any perceived changes they might attribute to the Blue Hills program.

\section{METHOD}

This IRB approved study was conducted using grounded theory methodology. Separate human subjects' protocols were approved by the university and the state Department of Corrections overseeing the facility in which Blue Hills ${ }^{2}$ was housed. Grounded theory is an inductive construction of knowledge that takes place between researchers and participants to develop a theory about the area of inquiry (Charmaz, 2000; Daly, 2007).

\section{Purposive Sampling}

Purposive sampling is a systematic approach to the selection of cases in qualitative research (Coyne, 1997; Creswell \& Plano Clark, 2011) and implies that information-rich cases are chosen for study inclusion (Patton, 2002). "Information-rich" cases are those from which one can best learn about the phenomena under study; in this instance, perceptions of change as a result of program participation, and spillover effects. Per our IRB protocol, we collaborated with a liaison at the correctional facility to identify current and past (but still incarcerated) participants of the Blue Hills program who would be interested in learning about the study. After a separate meeting with prison administrators and the research team, a second meeting was arranged with approximately 12 inmates at the facility, the first author, and the program liaison. It is during this meeting that the first author handed out IRB approved brochures and went over the details of the study; informed consent documents were left with program personnel and potential

\footnotetext{
${ }^{2}$ Blue Hills is a pseudonym for the actual program.
} 
participants. The study liaison then worked with the first author to schedule interviews with those men that were interested in participating. The first author traveled to the facility several weeks later, went over the informed consent documents, and subsequently interviewed 10 incarcerated male participants. It is in this manner that purposive sampling was used to identify incarcerated men currently or previously enrolled in Blue Hills and recruit them for interviews.

Data saturation. Our decision to stop interviewing after 10 interviews was based on several considerations discussed by qualitative scholars with regard to data saturation (Aldiabat \& Le Navenec, 2018). "Data saturation" is viewed as a key methodological criterion to determine when data collection should stop in grounded theory studies and is typically invoked when no new data or coding categories emerge in interviews (Charmaz, 2006; Glaser \& Strauss, 1971). Moreover, saturation can be enhanced when the researcher(s) is skilled and experienced in using qualitative methods, the scope of the study aim is clearly specified and not overly broad, the sample is "dense" (i.e., participants have broad and experiential knowledge of the topic under study), theory has been applied to frame the study, and the research employs a clear description of the analytic strategy (Aldiabat \& Le Navenec, 2018). These enhancements were believed to characterize the present study. Additionally, the challenges of conducting research in corrections settings are well-known and often involve significant barriers (Arditti, 2015; Arditti, Joest, Lambert-Shute, \& Walker, 2010; Byrne, 2005). Indeed, in corrections settings sometimes smaller, nonprobability samples are the "best that can be done" (Pope, Lovell, \& Brandl, 2001, p.13). Not surprisingly, this research faced administrative delays and a tight window with regard to accessing participants for interviews. Therefore, our decision to stop interviewing was based on practical as well as data saturation criteria.

With regard to data saturation, after each interview, the first author wrote extensive field notes. Recurring themes in these notes were apparent even after the first several interviews. After nine interviews, it seemed like data saturation was reached (no new codes were emerging, field notes captured a mostly positive experience in the program for the men with some caveats). A $10^{\text {th }}$ interview was conducted with a participant (pseudonym Sean) who was a "negative case" (i.e., he was "kicked out" of Blue Hills and his interview was conducted in the main corrections building rather than the barn setting) to ensure completeness of the data. Negative case analysis (used to disconfirm or breakdown themes) is an aspect of rigor in grounded theory studies and a feature of the constant comparative method (Taylor, Bogdan, \& DeVault, 2016). The identification of such cases allows for more nuanced thematic interpretation and the achievement of data saturation. The inclusion of a negative case, our utilization of the Aldiabat \& Le Navenec (2018) criteria to enhance saturation, along with the practical barriers that we faced in accessing the population under study informed the decision to stop interviewing after 10 participants.

\section{The Interview}

In-depth interviews were utilized to emphasize the value we placed on giving voice to those who are least likely to be heard: incarcerated persons who were in the program. We considered men in the program as "experts" of their own experience and therefore the best source of information regarding strengths and challenges of the Blue Hills program as well as how participation in the program may prepare them for reentry and perhaps contribute to an identity transformation aimed at desistance from crime (i.e., redemption scripts). Interviews were conducted in person by the first author at a correctional facility in a Mid-Atlantic state. With the 


\section{ARDITTI ET AL.}

exception of one participant (i.e., the "negative" case), all interviews were conducted in the barn setting in a private room where the program was implemented. The room had a window so that a Correctional Officer could see inside. Interviews were approximately 90 minutes long and comprised of mostly ${ }^{3}$ open-ended questions aimed at eliciting thick descriptions of program experiences and reflections on change. Thick description refers to a detailed account of patterns in the data that are described in context (Geertz, 1973; Holloway, 1997; Lincoln \& Guba, 1985).

In-depth interviews are useful for addressing sensitive topics, eliciting participant feelings, gaining an "interpretivist perspective" (i.e., the connections the individual sees among events and experiences), and align well with research on marginalized populations (Charmaz, 2006; Liamputtong, 2007; Mack et al., 2005). Consistent with Charmaz's (2001) criteria for qualitative interviewing for grounded theory analysis, the interview questions were designed to "define and explore processes" (pg. 678); in this case, processes centering around men's program experiences and their reflections on change. The questions were intended to tap into the subjective meanings participants held about their involvement in Blue Hills, their perceptions of strengths and challenges in the program, and how they felt they may have changed or "done anything differently" as a result of the program. The final question in the interview asked participants to "describe a positive future for yourself" in order to gain insight about men's hopes and dreams, and the extent to which experiences connected to Blue Hills might in fact connect with potential reintegration scenarios. Interview questions were informed by the first authors' previous experience conducting qualitative process evaluations for programmatic interventions for the Department of Corrections, the sensitizing concepts of the study, and Maruna's (2001) use of the Life History Interview (McAdams, 2008) to elicit narratives of redemption. Given the methodological design of the study, our intent was not to tease out causality about the effects of the Blue Hills program on key inmate outcomes (e.g., recidivism), but rather to gather detailed accounts of inmates' change experiences to develop a theory about the process of participating in a prison-equine program. All interviews were recorded and transcribed and lasted approximately 90 minutes.

\section{Population and Participants}

Population. Current Blue Hills participants and graduates of Blue Hills served as the subject pool for this study. All participants were men incarcerated at the Mid-Atlantic state work center (MSWC). The MSWC is a level 1, low-security facility that is part of the Mid-Atlantic Department of Corrections system. Low security facilities house nonviolent offenders that have reasonable physical and mental health (i.e., men do not have special or excessive health needs). The MSWC is located in a rural area not far from a major urban center and houses approximately 275 male inmates. Approximately $73 \%$ of the men housed at MSWC are Black, $27 \%$ are White, and less than $1 \%$ are categorized as "other race." A majority of the men, $38 \%$, at MSWC are between the ages of 30 and 39 years old, 30\% are age $40-49$ years, $19 \%$ are aged 18-29 years old, and 14\% were aged 50 or over. The average amount of "time served" at MSWC is 54.7 months (VADOC, 2016). Blue Hills participants were drawn from the general pool of men housed at MSWC based on their ability to meet eligibility requirements. While any IP at MSWC could apply to the program, IPs had to undergo several levels of screening before acceptance into the program. Eligibility for Blue Hills included: 1) IP did not smoke (due to flammable

${ }^{3}$ Structured questions were utilized at the onset of the interview to gather background and demographic information about the participants. 
materials, hay, at the barn), 2) liked horses, 3) no behavioral infractions, 4) correctional officers familiar with the IP believed it was a good fit based on their daily interactions and observations of the IP in other settings, and 5) the MSWC counselor evaluated the application and case file and moved it forward based on good behavior and absence of criminogenic risk. Once the MSWC counselor moved the application forward, it was reviewed by the Captain and the Assistant Warden. The final level of screening involved an interview with a five-person panel comprised of Correctional Officers and Blue Hills staff. The interview was designed to assess further the IP's reasons for wanting to participate in the program, goals upon reentry, and program fit. There were approximately 8-10 IP's in the program at a time with two cycles per year (spring and fall). Although not all IP's at MSWC had an equal chance of being accepted by Blue Hills due to strict eligibility parameters, all Blue Hills participants had an equal chance of participating in this research.

\section{Participants}

A total of ten current and former Blue Hills participants were interviewed utilizing a semi-structured interview approach during Fall, 2017. The interviewer asked scale and openended questions regarding family closeness and contact, closeness to the horses, overall feelings towards Blue Hills, and personal affect. The average age of the interviewee was 38, with the oldest participant 48-years-old and the youngest participant 25 -years-old. Half $(n=5)$ of the participants self-identified as Caucasian, two (20\%) self-identified as African American/Black, and three (30\%) self-identified as other or mixed race. Seven of the ten participants had children. Of those that had children, $20 \%$ of participants had six children, $20 \%$ of participants had three children, $10 \%$ of participants had two children, and $20 \%$ of participants had one child. The education levels ranged from some high school $(10 \%)$ to a master's degree $(10 \%)$; one-third of the participants earned a GED while incarcerated, 10\% earned a GED before prison, $20 \%$ earned a high school diploma, 10\% experienced some college, and 10\% graduated college. The length of sentence for each participant varied from 12 years to 3 years. Similarly, the number of sentences the participants had experienced varied from $50 \%$ having this current sentence as their first incarceration and 50\% having previously been incarcerated prior to the current sentence.

\section{Coding and Analysis}

Initial coding, in which each transcript line was coded into brief action statements (Charmaz, 2000), was independently conducted by three researchers of the study team to explicate initial and emerging codes. These codes represented major categories of "what" was in the data (Morse, 2008). Categories involved "participant relationships," "program environment," "identity" (i.e., content related to how participants viewed themselves), "Blue Hills Program" (i.e., text specific to the PEP and perceived benefits or challenges), and "reintegration" (i.e., content related to participants' narratives related to rehabilitation and their future after release). Axial coding (Strauss \& Corbin, 1998) was then used to establish relationships between coding categories based on similar circumstances, actions, and outcomes of the participants' experiences. Axial coding served as the basis for the themes derived and summarized in the results. Themes represented a deeper analysis of the data in terms of how categories tied together (Morse, 2008), and contributed to the development of a grounded theory model that specified the process of rehabilitative change for participants in Blue Hills. 


\section{ARDITTI ET AL.}

Based on coding around participant descriptions of their relationships, patterns in the data emerged concerning how Blue Hills participants formed reparative (i.e., therapeutic, healing) attachments with program staff and horses, as well as comradery with other men that were in the program cohort. Similarly, axial coding involving the environmental context of "the barn," or where the program is housed, and the reparative relational elements of Blue Hills led to our interpretation that participants developed redemptive identities centered on personal change and self-determination. These changes, in turn, seemed to connect with participant narratives about positive futures and life skills that typically serve participants well when they were released from confinement. Throughout the iterative coding process the constant comparative method (Charmaz, 2006; Glaser \& Strauss, 1967) was employed.

Trustworthiness was achieved via data saturation (discussed in the previous section) and through researcher immersion in the data and the iterative dialogue between researchers (Lincoln $\&$ Guba, 1985). To further enhance trustworthiness, triangulation was utilized through the use of in-vivo field notes, independent coding by three researchers and interactive dialogue amongst the research team. Specifically, the first three authors coded the data independently and compared the results during bi-weekly meetings. All sets of independent coding were highly consistent indicating compatible analysis. Further, the research team identified coding discrepancies and together agreed on the interpretation of the data by comparing field notes and data interpretation. Trustworthiness was further enhanced through ensuring thick descriptions of the data in the present dissemination of findings (Geertz, 1973; Lincoln \& Guba, 1985). Thick description increases transferability in grounded theory work so that the degree of fit between findings and interpretation may be assessed by those interested in applying the findings (Lincoln \& Guba, 1985).

\section{RESULTS}

Three aspects of the Blue Hills program that represented the thickest description based on participant narratives and interviewer field notes involved participant relationships with program staff and volunteers, bonds with the horses and the therapeutic value of spending time at the program location - the barn. We discuss these program aspects first and then turn our attention to explaining the grounded theory model of rehabilitative change. Pseudonyms are used for all participants.

\section{Relationships: The Blue Hills Family}

Relationships were central to the Blue Hills experience. Relational connections were formed as a result of day-to-day interactions between program participants and staff, between participants and between men and the horses under their care. These relationships and the resultant opportunities for men to form meaningful bonds with other people and horses seemed to be a critical feature of Blue Hills that connected to rehabilitative change. Here we focus on thick description concerning men's relationships with staff, program volunteers and the bonds they described with their horses.

Humanizing interactions. First and foremost, participation in Blue Hills broadly served a "humanizing" function in which men engaged in what they described as "normal" interactions. The central aspect of these interactions was that the men felt as if they were treated as a whole person rather than a "criminal." Participant comments such as "they [the Blue Hills staff] just treat you like actual human beings," "I get treated like a real person," or "they [the Blue Hills 
staff] treat you with respect" embodied the importance men attributed to humanizing interactions with staff and volunteers. Raymond elaborated: “... cause it's like I get treated like a real person. Because my brother in law, he is in corrections, he's an officer up in [Washington] D.C. and he told me, he's like straight up they tell us you guys [i.e., inmates] aren't people anymore. They actually train up to treat you subhuman. So, when you meet someone that actually talks to you like I'm not wearing orange, it's a little bit better, it feels better." Another participant, Michael, echoed this sentiment and explained: "they [program staff] just made you feel more welcomed in the world...they didn't look at you like you messed up, like you should be punished." Feeling stigmatized and devalued in their daily life, because they were prisoners, was a common sentiment among the study participants. Interactions within Blue Hills helped counteract these feelings and reminded men of their humanity. As Joe put it: "Yeah...people not just looking at you like you just locked up. That's the biggest thing [benefit of Blue Hills]."

Blue Hills' participants described opportunities to "be around positive people" who were viewed as sincere and truly interested in helping them. The belief that staff and volunteers where not getting paid, but were there because they wanted to be, seemed to enhance the perceived value of participants' relationships with staff and volunteers and their humanizing effect. One participant commented: "The people seem more sincere because to me they don't have to do it. They volunteer." Another Blue Hills participant expressed a similar feeling towards the benefits of interactions with volunteers: "I probably wouldn't have dealt with [experienced this] on the street and just seeing how other people act and meeting people who are really sincere about what they do." The interaction between the participant and volunteer facilitated growth and exposure to new relationships.

Joe contrasted the strengths of Blue Hills to other prison programs he had taken part in:

The strengths, the sincerity of being in here and working with people and working with the barn manager. The sincerity in the people and the sponsors [is what matters]. Not really wanting anything back, volunteers, people volunteering their time, and people really wanting to help you whether it is in here or on your way out. And people not looking at you like a criminal. They look at us like normal people.

However, this positivity was not universal as evidenced by Sean's comments about his interactions with staff. Although Sean enjoyed his relationships with the other men in the program and the horses, he reported feeling disrespected and unwelcomed by program staff and, to a lesser extent, the male correctional officers involved in Blue Hills. Sean explained his program involvement ended "acrimoniously" and described his interactions with program staff as "patronizing."

In sum, except for one participant, interactions with program staff and volunteers were described as sincere. These interactions seemed to nurture most participants, helped them to feel fully human and enabled normal day-to-day interactions. Moreover, participants seemed keenly aware that these humanizing interactions within the context of Blue Hills were entirely distinctive from their interactions with non-Blue Hills correctional staff when they were not in the program environment. 


\section{ARDITTI ET AL.}

\section{Bonds with Horses: "A Second Chance"}

Men discussed their attachments to the horses under their care as well as all the horses in the program. One participant stated that the horses were "easy to form a bond with... you can be very affectionate with the horses." Another participant discussed having an "automatic bond" with his horse. Jeff discussed at length his deep connection to his horse and summed things up: "The strongest bond in this program I believe is the bond between the inmate and the horse." Overall, participants found their time with the horses to be rewarding and helpful to them on several levels.

A sense of purpose. First, participants' relationships with their horses provided men with a purpose. As Derick commented: "It helps people... having a sense of purpose, know you have to take care of something...that this horse depends on you...it gives you a lot of strength." Caring for the horses gave men a sense of responsibility and something to think about besides serving their time. As Joe explained: "I think about the horses a lot, and most people I deal with I talk about the horses." Another participant stated: "Shows you responsibility. It [caring for the horse] gives you a sense of purpose."

The responsibilities involved with horsemanship gave men an alternative (and positive) focus that helped relieve stress and made their days more palatable. Raymond depicted the standard day for a Blue Hills participant: "We leave the gate [main correctional facility] at like 7:20 - 7:30. By the time feedings done, we walk the horses down it's like 10. By the time we get done grooming it's noon. So, the day does fly by." Several participants explained how this strict schedule and working with the horses kept them out of trouble. Joe described his experience: "Yeah just kind of in a way keep me sane. Keeps me away from a lot of nonsense and then it keeps a lot of nonsense away from me... I can actually be positive and actually go out there and stay out of trouble and not think about negative things or doing something negative," and "all the guys down here are pretty much the ones that are staying out of trouble up there too."

Contributing to the sense of purpose were men's perceptions that their involvement in the program and, more specifically their direct work with horses was preparing them for the "real world" upon reentry. Several men equated their program participation as "bettering themselves" or using their farrier skills to get a job. Brent, a program graduate who served as a teaching assistant for the program at the time of the study, talked about the horse farrier skills he gained: "So I'm kind of depending on the program to help me out a little bit. And use the skills that I've acquired down here to maybe get a job at a farm where you can live there, living quarters maybe or something of that nature."

Even if experience with horses was not viewed as a primary form of employment upon release, participants still believed the experience would be helpful to them. Raymond stated: "I mean this grooming thing might be lucrative. If I go that way, I don't know if I would. But it will always be in my back pocket." Michael expressed a similar perception: "It's just another option that you have for when you leave here... if you want to go get a part-time job and get your foot in the door somewhere. Horse people to me are real nice people." In sum, men derived benefit from their time directly interacting with horses as well as a sense of purpose by preparing for an unknown future after incarceration.

Emotional intelligence. Second, relationships with horses helped to improve mood, regulate emotions and develop emotional intelligence. Emotional intelligence involves the ability to express and understand one's emotions as well as how to interact empathically with others (Mayer \& Salovey, 1997). As Brent stated: "If I have a bad day I get around the horse, the 
horse might be playing with you or something and get you in a better mood." Gary, who had experiences with animals as a child, explained: "I grew up on a farm, so it's always been nice to work around animals. It has always relaxed me. Put me in a good mood. It's not stressful." Another participant, Austin, acknowledged how his relationship with his horse helped him cope with stress: "It's more of a stress thing for me they help with or its...a companion thing I think." Still, another participant noted that his interactions with his horse brought out "his sensitive side." The importance of sensitivity was reflected by the following comment from Chris: "I can honestly say I haven't found myself intimidated by them at all, but I've always been scared of what I might do to harm them."

Participants discussed the emotional intelligence gained through their bonds with horses and the necessity of learning to read their horse's mood. Chris explained: "These horses - even my same horse - different day have a different attitude. He might not be a little cranky today or tomorrow, but ... its teaching me to deal with people." Similarly, Derick stated: "You really have to pay attention to learn their personalities and that is helping me as far as people and in general, too. I got to watch people's body language to know where we stand at." Horses then seemed to help men gain confidence in their ability to interact empathically. Jeff discussed his willingness to put his horse first: "I found that with this program I, because of the attachment to the horses, I was able to put them first above a lot of other things. I would probably do anything for them." Michael discussed how reassuring he found the bond with his horse and how this helped him with others: "...just needed a few things I think like reassurances of the things and showing I can work with the horses on another level and talking to people and understanding things. It helped me a little bit." Similarly, other participants discussed building trust with their horses, or becoming more attentive and patient as a result of their relationships with their horses. The following comments reflected how relationships with horses helped participants fine-tune empathy, emotions and relational skills.

For example, Austin had been in and out of prison for more than 20 years and was ready to make this sentence his last. He developed a deep relationship with the horses once he saw that they accepted him. This allowed him to "build a bond, a friendship first. And it's all about them trusting you first, and you can't push your way into that." With time, he became more patient because "them horses will definitely teach you patience because they are gonna do it when they're ready." Another participant, Brent, saw a lot of himself in the horses. He reported being a quiet guy, just like the horses and stated: "I know how animals feel and I like that I can have someone to relate to. Someone that understands me." Brent described how his relationship with his horse began to improve his attentiveness and emotional acuity. He explained: "So it made me a little better as far as paying attention, dealing with animals, having compassion for animals ... [my horse] makes me a more open person." Jeff shared a similar sentiment and explained the connection with the horse began by learning how to listen. Jeff explained this communication process: "horses don't talk ...it's based on body language and affection...It's a lot of observation... so its heightened listening almost..."

Overall, participants seemed to relate to their horses in terms of personality and emotions and worked to improve themselves as a result. Austin discussed his transformation as a result of learning to interact with his horse: "I've been abrasive all my life...but now I see there is different ways to deal with life. You don't always have to put a wall up and scare people into doing what you want them to do. And you get better outcome with that." Derick gained perspective about how others may see him because of what he believed he had in common with 


\section{ARDITTI ET AL.}

his horse: "Being around the animals and they can't talk so I got to pay attention. I can deal with that. I feel how other people feel towards me now because I'm not a talker."

Acceptance and support. In addition to helping men have a sense of purpose, cope with the stress of incarceration, and improve their emotional acuity and relational skills, bonds with horses provided men with a sense of safety and security they may not have had with people in their lives (past or current). Similar to men's sense that they were treated with respect and valued by program staff, study participants appreciated the nonjudgmental nature of their relationships with their horses. Participant comments such as: "I'm in orange, but they [horses] don't treat me like I'm in orange," "These horses don't reject you," and "The horses give you a second chance," were indicative of the value men put on feeling accepted for who they were, in the moment. Chris, who suffered from a degenerative ocular disorder and struggled with feelings of rejection all his life, described his relationship with his horse as "one of acceptance..." that helped him to "stay steady and be true to myself." He elaborated: "I wanted to be accepted everywhere I went and ... I always could kind of make a joke and fit in, but sometimes you don't need to fit in, and that's kind of what these horses are teaching you." Bonds with horses not only provided a sense of acceptance but became an important source of support for participants. Sean acknowledged that the animals in his life served as a "support system." Another participant, Michael, discussed the support he received from his horse: "He was like a therapeutic horse to me. I could talk to him. His name was Clem... it's like you could vent to him if you needed a hug, he would give you back the love that you needed to help you out."

Loss. Finally, bonds with horses seemed to run deep. Perhaps the most poignant indication of the depth of these attachments involved how participants felt upon their separation from their horses due to adoption or the end of their participation in Blue Hills. Men discussed in depth the emotional pain of seeing one of their horses being adopted while under their care. Jeff described the experience: "You don't see many guys cry in prison, but he had tears in his eyes when his horse got adopted away." Another participant found comfort in the fact that although his horse was adopted, it would help others. Brent said, "I was sad at first. But, at the same time, I felt that he was going to a better place to help other people. It could be a kid out there who was autistic or somebody that has PTSD or something else or mental issues that the horse may give them a better day like he was giving me."

In addition to the possibility of loss stemming from a horse's adoption, several men discussed what it was like after participants' graduated from Blue Hills and no longer saw the horses. Jeff, a recent graduate of the program, spoke about the loss experienced once his time in Blue Hills was over and he had to cut ties with the horses:

When you come to prison a lot of things get taken away from you, when you do this program and this program ends you get the horses taken away from you. And so that's a very hard thing. A lot of the guys who have not remained down here I know have... there is one gentlemen up there that was in the previous class prior to mine. He went into a depression for a couple of months. That's a real hard thing to swallow because you have a horse every day, 7 days a week, 65 hours a week and when the program ends you go to zero contact with the horse.

The irony was that the interview afforded Jeff a glimpse of the horses he once knew because it permitted him to return to the barn environment. Jeff discussed the context of his and other participants' loss of contact with their horses: 
I: There is no continuity? [i.e. after program ends]

Jeff: No. And it's a very hard thing to take. There are times when I work elsewhere on the farm and I hate coming down here because it's one of those things you get the horse taken away and then you get to see it again but you can't really interact with it. It's tough.

I: Do you see any of your horses today?

Jeff: Oh yeah.

I: How are you feeling?

Jeff: It's okay. I sat very quietly over there and said hello, but I'm still very attached to him so it's tough.

I: Because they don't let you have contact after?

Jeff: Right.

I: No visits?

Jeff: Yeah.

I: Do you think the staff are tuned into that issue?

Jeff: I don't know if they are or not. I think it might be something that is missing.

I: I have heard about horses being adopted out. Did that happen to you?

Jeff: It didn't happen to me thank goodness. I actually had my favorite horse, somebody came to look at him, but he's such a therapeutic type horse they decided to make him a therapy horse and removed him from the adoption list so I didn't lose him.

I: Were you worried when this person came?

Jeff: Oh yes. Absolutely, excruciatingly worried

I: Painful?

Jeff: Yeah, I didn't sleep. Called my family every day. And I saw guys lose their horses. There was another gentleman that was down here with me that I talked to a lot, he cried... And he is someone who lost his wife and a couple of other family members while he's been in here.

Loss of contact with horses was profoundly felt by some Blue Hills participants and reflected their deep attachments to the retired thoroughbreds. The sense of loss was further intensified by other relational losses and institutional practices that prohibited further contact.

\section{The Barn Environment: "A Different World"}

The Blue Hills program was housed in a barn that was located down a hill in a valley approximately $3 / 4^{\text {th }}$ of a mile from the main correctional facility. Geographically, it was quite separate from the main building and surrounded by fields and meadows where horses and other livestock grazed. Men were shuttled to the barn by Correctional Officers, some of whom were the main correctional officers at the barn and quite familiar with the participants.

Freedom. The barn environment seemed to matter a great deal to Blue Hills participants and afforded prisoners a different kind of experience characterized by a sense of freedom and normalcy that could not be achieved elsewhere given the stresses of routine prison life "up on the hill." It should be noted that there were no fences surrounding the barn. As Joe stated: "It [Blue Hills] gives you a sense of not being incarcerated somewhat. And it helps with keeping me calm. 


\section{ARDITTI ET AL.}

It relieves stress...I just love being down here." Brent echoed these sentiments: "Where back at the prison it's just you gotta deal with that environment all day long, and that can really stress you out. You come down here and it's like a stress reliever." Jeff elaborated: "When you come down here you get a lot of freedom to be able to do certain things as far as being able to go out and get horses and walking them through the fields and pastures by yourself." When asked what he liked about Blue Hills, Raymond responded: "I guess the freedom, the quote, unquote freedom, like you know it's a really relaxed environment."

The opportunity to spend time at the barn afforded a distinct chance to escape the routine and difficult conditions of the correctional facility. As one participant stated: "You can come down here and have a little peace and quiet... down here it's like everybody's the same." At the end of the day, upon returning to "the hill" (the prison dorms), thinking about the barn helped. Joe said, "I feel a lot better, I go up on the hill, I think about this program more than anything else." But upon finishing the program, men missed the sense of freedom they experienced down at the barn. Sean said, “... being outside I like. That's one thing I miss now, is I can go out in the yard here but that's a far cry from being in the middle of a pasture."

Brent summed up the distinction between prison and barn: "When I'm down here, it's like a different world. Like I said, I try to leave all my problems up there. I don't bring it down here and just enjoy the time with the horses." Joe's comments seemed to expand on this point: "I feel like you can talk to them [Blue Hills staff] a little more closer than you could with the COs [on the hill]. I mean it's just, I guess, feels like a different environment. Like two different environments." Michael summarized the differences as "you try to get in the right circle with the people that are smart and willing to help you and help make you think and stuff, you'll do better. More positive influences instead of negative." Overall, the barn environment contributed to men's sense of normalcy and humanity because it permitted them precious moments of freedom, alone time, peace, and of course, time with horses. Participants discussed the benefits of "being with nature" and "walking in the fields with the horses."

Self-determination. Self-determination, which encompasses the ability to initiate and control behavior, arises from specific relational and environmental factors such as freedom, autonomy, and connection with others (Deci \& Ryan, 1985; Ryan \& Deci, 2000). Given the relational context and greater freedom of the barn environment, it was not surprising that participation in Blue Hills afforded study participants a sense of self-determination in terms of making decisions about when and how to get things done and move through their day. Raymond explained: "There's not so much structure as there is up on the hill. On the hill, you move when they say...it's a little less structured [in the barn]." He continued to elaborate on the importance of "getting to decide" when to enact horse-related tasks: "no one is like over top of you at all times telling you what to do. You have a job here, and you just gotta get it done whether you do it first thing or you wait a little bit."

Indeed, opportunities for self-determination seemed to arise given the more relaxed environment at the barn. Raymond explained, "On the hill, you move when they say even though they let us walk in and out during rec and all that you know it's a little more ... less structured. And it's just nice to be around animals." These statements indicate that tightly-controlled environments inherent to many traditional incarceration settings may foster agitation, hypervigilance and prolonged stress. Brent highlighted this process, "Back at the prison it's just, you gotta deal with that environment all day and it can really stress you out. You come down here [the barn] and it's a stress reliever." Another participant shared, "You know what? Prison is 
a lonely, lonely place... I'm more comfortable with myself down here [the barn] then, I mean more laid back, not threatening."

The less structured environment of Blue Hills demonstrated that even a nominally higher degree of trust and freedom may provide participants with self-determination opportunities that facilitate stress-relief, deeper introspection, and personal growth. Joe's comments eloquently reflected this point: "It [being at the barn in the program] gives you a sense of not being incarcerated somewhat. And it helps with keeping me calm. It relieves stress a whole lot working with the horses. I never worked with horses before, so now I just love being down here. It has calmed me down a lot and taught me a lot to deal with stress and the way I think about things. Listening to other people a little more and listening to other people's input."

\section{A Grounded Theory of Rehabilitative Change}

Grounded theory coding yielded themes of rehabilitative change within Blue Hills as well as responses pertaining to how Blue Hills connected to reintegration. Figure 1 (see appendix) summarizes the theorized relationships among the thematic areas that were identified in the men's narratives. Participants clearly identified that both relationships and the barn environment were important rehabilitative mechanisms within the Blue Hills program. Deeper analysis of the data indicated these influences coalesced in a manner that appeared to facilitate a process of rehabilitative change characterized by three within domain "spillovers" of the program: 1) development of emotional intelligence, 2) redemptive identity or the ability to see oneself in a new way (e.g., having a purpose and as a person of worth), and 3) reparative attachment experiences. They are considered "within domain" in that they are specific rehabilitative change processes that occurred within the individual but were not necessarily an explicit goal of the program.

In turn, we theorized that these rehabilitative change components contributed to positive, "across domain" spillovers related to family, community, and positive reentry scenarios. Although reintegration was yet to be achieved, it was on participants' minds, and respondents were often explicit about how they believed program participation would translate into successful reentry. Across domain reintegration responses encompassed participant descriptions of positive futures for themselves "outside of prison walls," stronger connections with family and children, and a sense that they were better prepared for reentry as a result of their participation in Blue Hills. While space constraints limit our presentation of thick description related to across domain spillovers, Table 1 provides a brief overview of exemplars from participant narratives that illustrate content pertaining to reintegration spillovers.

\section{Table 1. Reintegration Response Exemplars}

Reintegration Responses

- Connection with

Family and

Community

- Positive Futures
"I think it (program) really gave me a lot to talk about with them (family). And I think it was good for them to see I wasn't just sitting there in a facility not making any progress...not growing in any way."

"I still want to stay in contact with this program (upon release)...maybe find a way to help kids that are having problems 


\section{ARDITTI ET AL.}

\begin{tabular}{|l|l|}
\hline \multirow{2}{*}{ Life Skills } & $\begin{array}{l}\text { at home...working with kids and helping them so they can stay } \\
\text { out of prison." } \\
\text { Like the topics we (staff) go over, knowing how to talk to people } \\
\text { or expressing feelings. I think that can help people when they get } \\
\text { out." } \\
\text { "It's just another option that you have for when you leave here." }\end{array}$ \\
\hline
\end{tabular}

Our grounded theory findings illuminate the redeeming power of humanizing relationships with persons and horses and a distinctly atypical (relative to the typical prison structure) day to day experience in a natural "horse centered" environment (i.e., the barn). Based on our analysis, we were able to explicate a theory of rehabilitative change that specified key within domain spillovers with the potential to contribute to successful community and family reintegration after release from prison. The grounded theory model is a starting point to advance how PEPs might promote change, and its veracity can be tested using larger samples and longitudinal designs that follow men through release and reintegration after incarceration.

\section{DISCUSSION}

Traditional prison environments are highly constrained and inconsistent with the demands and tempo of life outside of prison walls (Travis, 2005). Additionally, scholars have noted the widespread disrespect that prisoners experience in correctional settings. Such disrespect, along with correctional training of prison staff as "impersonal agents of authority" (p. 325 ) is central to the dehumanization of prisoners (Johnson, Rocheleau, \& Martin, 2017). Study findings suggest that PEPs can be a humanizing respite for IPs and are particularly appropriate for incarcerated populations. Moreover, given inherent opportunities within Blue Hills for reparative connection and identity development, the program appears responsive to the mental health needs of many IPs who struggle with histories of victimization and trauma (Wolff, Huening, Shi, \& Frueh, 2014). Indeed, similar to the extant literature profiling the incarcerated (e.g., Arditti, 2012), many participants in the study revealed personal family histories characterized by traumatic loss and instability. The Blue Hills barn represents a safe space for IPs to practice interpersonal skills, engage in socioemotional learning and have choices about the way things evolve in their lives. Such an approach is consistent with Maruna's desistence paradigm, which focuses on the views and voices of correctional clients themselves and offers prisoners programs that "make sense" to them and provide positive acknowledgment of their efforts (Maruna \& Label, 2010). The role of others in recognizing and supporting efforts at reform appears to be inherent within the Blue Hills program, mostly through men's interactions with staff and the affirmative and immediate feedback they receive from the horses under their care.

The present study, however, is not without its limitations, and our findings should be viewed with caution. Participants in the Blue Hills study were a highly screened, wellfunctioning group of IPs. Therefore, because of self-selection, it is unknown whether our findings would transfer to other inmate populations or other PEPs. Additionally, because of our qualitative methodology, it is unknown as to whether participation in previous treatment or educational programs influenced participant narratives or whether participation in Blue Hills had 
any causal impact on adjustment during confinement or recidivism after release. Although we cannot make causal determinations from the study findings, our grounded theory offers a framework for how the Blue Hills PEP may contribute to change and promote well-being among incarcerated participants.

Study limitations notwithstanding, Blue Hills, and PEPs more generally, are likely successful to the extent they serve to normalize day-to-day interactions, provide important opportunities for skill-building and self-determination, and permit chances for participants to form reparative attachments and develop redemptive or "prosocial" identities. Self-determination ideals have high generalizability with regard to positive health behaviors and vocational outcomes (Garrin, 2014) including successful correctional education (McKinney \& Cotronea, 2011) and prisoner reentry (Blessing \& Golden, 2004; Lindahl, 2007). Similarly, identity work, in which individuals develop a positive and capable view of themselves, provides a means for the incarcerated to escape their shame and is believed to be foundational to desistence from crime and successful reentry scenarios (Maruna, 2001; Maruna \& Ramsden, 2004; Paternoster et al., 2016).

Relational and environmental mechanisms of change (as articulated by our grounded theory model) are consistent with principles of attachment theory (Bowlby, 1969), self determination theory (Deci \& Ryan, 1985; Ryan \& Deci, 2000) and a strengths-based resettlement approach (Burnett \& Maruna, 2006). These interdisciplinary frameworks emphasize the importance of meaningful connections and the ability to make choices to enhance pro-social self-concepts, competence and relatedness. Traditional incarceration is a setting devoid of these factors, and in fact, may promote the criminogenic behaviors that result in future recidivism (Perelman et al., 2012). Indeed, social isolation and disconnection, hallmarks of the "pains of imprisonment," are considered major sources of human suffering (Haney, 2001; Sykes, 1958). Prisoners may develop an impenetrable "prison mask" characterized by withdrawal into self, not trusting others, emotional flatness and an inability to "initiate behavior of one's own." (Haney, 2001, para 25). The resultant isolation, disconnection and immobilization prevent movement back into healthy relationships and self-autonomy (Jordan, 2000) - both of which are components of successful reentry into family and community life after incarceration. The relationships and barn environment are powerful components of the Blue Hills program that potentially provide reparative experiences which, in turn, could promote future desistance. However, a caveat of Blue Hills involves participants' feelings of ambiguous loss once the sixmonth program was over because they were disallowed from interacting with the horses and the staff with whom they have formed bonds. The abrupt and complete cut-off from staff and horses is inconsistent with the mental health needs of incarcerated participants that may stem from traumatic separation and personal histories of loss (Miller \& Najavitis, 2012). We recommend greater continuity in these connections for participants to sustain program benefits and so as not to activate loss-related trauma.

Horses may be particularly attuned for reparative attachment work as well as accelerate the development of pro-social skills and emotional intelligence (McPhederon, 2009; Payne et al., 2016). Horses are believed to attune to human emotions in a unique manner and are quite attentive to their handlers (Donato, 2017; Hausberger, Roche, Henry, \& Visser, 2008; Keaveney, 2008). Moreover, horses have a unique ability to interpret and respond to human body language and emotion (Keeling, Jonare, \& Lanneborn, 2009), promoting empathic interactions between the handler and the horse. Such interactions have a strong potential to influence the individual's capacity to feel empathy for another human being (McPhedran, 2009). Empathy is a core 


\section{ARDITTI ET AL.}

component of emotional intelligence, which, in turn, influences the quality of interpersonal and interspecies relationships (Payne, DeAraugo, Bennett, \& McGreevy, 2016) as well as positive resettlement outcomes (Burnett \& Maruna, 2006). Horses possess several unique behavioral qualities that define their relationship with humans and promote empathic connections. Horses are interactive with humans and can recognize and react to changes in human behavior (Hausberger et al., 2008; Keeling et al., 2009). Several participants in this study indicated that the horses taught them to be more patient and less reactive. Because of their size and power, horse responses are hard to ignore, yet these animals rarely react aggressively unless pushed into a perceived life-threatening situation. The horse's reaction to human emotion is unencumbered by preconceptions or social stigma, allowing the animal's response to be perceived as more authentic. Additionally, the human-equine relationship also provides opportunities to experience touch and a physical connection with another living creature further breaking isolation and fostering acceptance and psychological security. Daily maintenance of horses requires touch in the form of grooming and scratching and horses can respond to human grooming with behaviors that suggest they enjoy the experience. Thus, the horses' ability to modify their reactions as human behavior changes establishes the human-equine relationship as a valuable source of meaningful connections based on mutual empathy and connection.

\section{IMPLICATIONS AND FUTURE RESEARCH}

Our exploration of Blue Hills suggests that its essential "success" may rest on its ability to permit experiences of reparative attachment, mutual empathy and identity work centered on self-worth and a sense of agency. The results of the program may go well beyond vocational skills pertaining to horsemanship and contribute to positive futures based on participants' abilities to develop and sustain healthy connections. Although our findings are qualitative and the limitations of the study noted, findings were encouraging in terms of how men described their experiences in the program and how they believed they changed as a result. The foremost implication is that PEPs should be structured to include components that may inherently promote experiences of reparative attachment and self-determination. For example, reparative attachment experiences may be enhanced to the degree that the staff strive to model warmth, encouragement, empathy and respect. Further, PEPs that are structured with opportunities for participants to experience a sense of agency, such as tasks with varying levels of supervision, may help promote a sense of competency and self-guided action. It is recommended that these experiences be scaffolded to incorporate increasing degrees of trust and responsibility.

Another important implication from these findings is that the location of the carceral setting should also be considered. The PEP in the present study is located in a rural area with a number of local horse barns and equestrian centers. Blue Hills may help promote positive reentry scenarios by providing vocational skills that are matched to the employment needs of the community. Finally, while prison-based animal research is emerging, it has not caught up to the widespread use of animals in correctional programming (Furst, 2006). There is a need to test theoretical models (such as the one advanced here) to evaluate the causal pathways of rehabilitative change within PEPs. While random controlled trials may be unlikely in evaluating PEP programs within an institution, (see Fournier, Geller, \& Fortney, 2007) future research that involves group randomization among several different correctional populations (i.e., some prisons will be assigned a program while others will not) permit for greater generalizability and would facilitate program evaluation and refinement. 


\section{CONCLUSION}

PEPs like Blue Hills are unique and potentially powerful prison-based interventions whose full effects are not yet completely understood. The present research represents a first step in documenting that the scope of the Blue Hills program may have important within and across domain spillovers. Study findings suggest that relationships with horses, staff, and the barn environment itself gave Blue Hills' participants a reprieve from the typically incapacitating pains of imprisonment. Such a reprieve, in conjunction with opportunities to practice relational skills, develop emotional intelligence and see oneself as a valued person with purpose, is a highly therapeutic context for healing and shame management (Maruna \& Ramsden, 2004). Overall, the relational and environmental opportunities offered by Blue Hills are consistent with therapeutic approaches within corrections aimed at helping people relinquish strategies of disconnection and negativity in relationships through the promotion of empathic, growth-fostering bonds (Jordan, 2000) and self-determination (McKinney \& Cotronea, 2011).

\section{REFERENCES}

Aldiabat, K., \& Le Navenec, C. (2018). Data saturation: The mysterious step in grounded theory method. The Qualitative Report, 23(1), 245-261.

Angelucci, M., \& DiMaro, V. (2015). Program evaluation and spillover effects. Policy Research Working Papers. doi:10.1596/1813-9450-7243

Arditti, J., Joest, K., Lambert-Shute, J., \& Walker L. (2010). The role of emotions in fieldwork: A self-study of family research in a corrections setting. Qualitative Report, 15(6), 13871414.

Arditti, J. (2012). Parental incarceration and the family: Psychological and social effects of imprisonment on children, parents, and caregivers. New York, NY: NYU Press.

Arditti, J. (2015). Family process perspective on the heterogeneous effect of maternal incarceration on child wellbeing. Criminology \& Public Policy, 14(1), 169-182.

Bachi, K. (2013). Equine-facilitated prison-based programs within the context of prison-based animal programs: State of the science review. Journal of Offender Rehabilitation, 52(1), 46-74.

Bachi, K. (2014). An equine-facilitated prison-based program: Human-horse relations and effects on inmate emotions and behaviors (Unpublished doctoral dissertation). City University of New York, New York, NY.

Blessing, C., \& Golden, T. (2004). Inmate to citizen: Using person-centered practices to facilitate the successful re-entry of inmates. Cornell University School of Industrial and Labor Relations; Employment and Disability Institute. Retrieved from https://digitalcommons.ilr.cornell.edu/cgi/viewcontent.cgi?article $=1126 \&$ context $=$ edicol lect 


\section{ARDITTI ET AL.}

Bowen, G. (2006). Grounded theory and sensitizing concepts. International Journal of Qualitative Methods, 5(3), 12-23.

Bowlby, J. (1969). Attachment and loss. New York: Basic Books.

Burnett, R., \& Maruna, S. (2006). The kindness of prisoners: Strengths-based resettlement in theory and in action. Criminology \& Criminal Justice, 6(1), 83-106.

Byrne, D. (2005). Complexity, configurations and cases. Theory, Culture \& Society, 22, 95-111.

Cantora, A. (2013). Building grounds for release: Women's perceptions of a community corrections program. Journal of Qualitative Criminal Justice and Criminology, 1(2), 197220.

Charmaz, K. (2000). Grounded theory: Objectivist and constructivist methods. In N. Denzin \& Y. Lincoln (Eds.), Handbook of qualitative research (2nd ed., pp. 509 - 535). Thousand Oaks, CA: Sage.

Charmaz, K. (2001). Qualitative interviewing and grounded theory analysis. In J. Gubrium \& J. Holstein (Eds.), Handbook of interview research: Context \& Method (pp. 675-694). Thousand Oaks: Sage.

Charmaz, K. (2006). Constructing grounded theory. Thousand Oaks, CA: SAGE Publications.

Coyne, I. (1997). Sampling in qualitative research. Purposeful and theoretical sampling; merging or clear boundaries?. Journal of Advanced Nursing, 26(3), 623-630.

Creswell, J., \& Plano Clark, V. (2011). Designing and conducting mixed method research. $\left(2^{\text {nd }}\right.$ ed.). Thousand Oaks, CA: Sage.

Daly, K. (2007). Qualitative methods for family studies and human development. Thousand Oaks, CA: Sage.

Deci, E., \& Ryan, R. (1985). Intrinsic motivation and self-determination in human behavior. New York: Plenum.

Donato, A. (July 30, 2017). Everything you need to know about horse therapy. Firsthand. Retrieved from https://www.cbc.ca/firsthand/m features/everything-you-need-to-knowabout-horse-therapy.

Doty, J., Davis, L., \& Arditti, J. (2017). Cascading resilience: Leverage points in promoting parent and child well-being. Journal of Family Theory and Review, 9(1), 111-126.

Durose, M., Cooper, A., \& Snyder, H. (2014). Recidivism of prisoners released in 30 states in 2005: Patterns from 2005 to 2010. Washington, DC: Bureau of Justice Statistics.

Foster, H., \& Hagan, J. (2007). Incarceration and intergenerational social exclusion. Social Problems, 54(4), 399-433. 
Fournier, A., Geller, E. S., \& Fortney, E. (2007). Human-animal interaction in a prison setting: Impact on criminal behavior treatment progress, and social skills. Behavior and Social Issues, 16, 89-105.

Furst, G. (2006). Prison-based animal programs: A national survey. The Prison Journal, 86(4), 407-430.

Garrin, J. (2014). Self-efficacy, self-determination, and self-regulation: The role of the fitness professional in social change agency. Journal of Social Change, 6(1), 41-54.

Geertz, C. (1973). The interpretation of cultures: Selected essays. New York: Basic Books.

Glaser, B. \& Strauss, A. (1967). The discovery of grounded theory: Strategies for qualitative research. Chicago: Aldine Publishing Company.

Glaser, B., \& Strauss, A. (1971). Status passage: A formal theory. Chicago, IL: Aldine.

Greener Pastures: A Second Chance Program. (2018). Retrieved from https://www.trfatjamesriver.com/about-us

Haney, C. (2001, Dec). From prison to home: The effect of incarceration and reentry on children, families, and communities [The psychological impact of incarceration: Implications for Post-Prison Adjustment]. Retrieved from: https://aspe.hhs.gov/basicreport/psychological-impact-incarceration-implications-post-prison-adjustment

Hattery, A., \& Smith, E. (2010). Prisoner Reentry and Social Capital. New York, NY:Lexington Books.

Hausberger, M., Roche, H., Henry, S., \& Visser, E. (2008). A review of the human-horse relationship. Applied Animal Behaviour Science, 109(1), 1-24.

Hlavka, H., Wheelock, D., \& Jones, R. (2015). Ex-offender accounts of successful reentry from prison. Journal of Offender Rehabilitation, 54(6), 1-23.

Hochstetler, A., \& Copes, H. (2015). Qualitative criminology's contributions to theory. In A. Piquero (Ed.), The handbook of criminological theory (pp. 497-520). New York, NY: John Wiley \& Sons.

Holloway, I. (1997). Basic concepts for qualitative research. Malden, MA: Blackwell Science.

Johnson, R., Rocheleau, A., \& Martin, A. (2017). Hard time: A fresh look at understanding and reforming the prison ( $4^{\text {th }}$ Edition). Malden, MA: Wiley.

Jordan, J. (2000). The role of mutual empathy in relational/cultural therapy. Journal of Clinical Psychology, 56(8), 1005-1016.

Keaveney, S. (2008). Equines and their human companions. Journal of Business Research, 61(5), 444-454. 


\section{ARDITTI ET AL.}

Keeling, L., Jonare, L., \& Lanneborn, L. (2009). Investigating horse-human interactions: The effect of a nervous human. Veterinary Journal, 181(1), 170-171.

Langan, P., \& Levin, D. (2002). Recidivism of prisoners released in 1994. Federal Sentencing Reporter, 15(1), 58-65.

Liamputtong, P. (2007). Researching the vulnerable: A guide to sensitive research methods. Thousand Oaks, CA: Sage.

Liem, M., \& Richardson, N. (2014). The role of transformation narratives in desistance among released lifers. Criminal Justice and Behavior, 41(6), 692-712.

Lincoln, Y., \& Guba, E. (1985). Naturalistic inquiry. Beverly Hills, CA: Sage.

Lindahl, N. (2007). Venturing beyond the gates: Facilitating successful reentry with entrepreneurship. New York, New York: John Jay College of Criminal Justice, The Prisoner Reentry Institute. Retrieved from: https://www.reentry.net/download.cfm?id=109626

Mack, N., Woodsong, C., MacQueen, K., Guest, G., \& Namey, E. (2005). Qualitative research methods: A data collector's field guide. Research Triangle Park, NC: Family Health International.

Maruna, S. (2001). Making good: How ex-convicts reform and rebuild their lives. Washington, D.C.: American Psychological Association.

Maruna, S. \& Ramsden, D. (2004). Living to tell the tale: redemption narratives, shame management and offender rehabilitation. In A. Lieblich, D. McAdams, \& R. Josselson (eds.), Healing plots: The narrative basis of psychotherapy (pp. 129-149). Washington, DC: American Psychological Association.

Maruna, S. \& Label, T. (2010). The desistance paradigm in correctional practice: From programmes to lives'. In F. McNeill, P. Raynor, and C. Trotter (Eds.), Offender supervision: New directions in theory, research and practice (pp. 65-89). Cullompton, Devon:Willan Publishing.

Masten, A., \& Cicchetti, D. (2010). Editorial: Developmental cascades. Development and Psychopathology, 22(3), 491-495.

Mayer, J., \& Salovey, P. (1997). What is emotional intelligence? In P. Salovey \& D. Slutyter (Eds.), Emotional development and emotional intelligence: Educational implications (pp. 3-31). New York, NY: Basic Books.

McAdams, D. (2008). 'The Life Story Interview.' Retrieved from https://www.sesp.northwestern.edu/foley/instruments/interview/

McKinney, D., \& Cotronea, M. (2011). Using self-determination theory in correctional education program development. The Journal of Correctional Education, 62(3),175-193. 
McPhedran, S. (2009). A review of the evidence for associations between empathy, violence and animal cruelty. Aggression and Violent Behavior, 14(1), 1-4.

Miller, J., Copes, H., \& Hochstetler, A. (2015). The history and evolution of qualitative criminology. In H. Copes \& J. Miller (Eds.), The Routledge handbook of qualitative criminology (pp. 3-21). New York: Routledge.

Miller, N., \& Najavits, L. (2012). Creating trauma-informed correctional care: A balance of goals and environment. European Journal of Psychotraumatology, 3.

Morse, J. (2008). Confusing categories and themes. Qualitative Health Research, 18(6), 727728.

Paternoster, R., Bachman, R., Kerrison, E., O'Connell, D., \& Smith, L. (2016). Desistance from crime and identity: An empirical test with survival time. Criminal Justice and Behavior, 43(9), 1204-1224.

Patton, M. (2002). Qualitative research and evaluation methods. ( $3^{\text {rd }}$ ed.). Thousand Oaks, CA: Sage.

Payne, E., DeAraugo, J., Bennett, P., \& McGreevy, P. (2016). Exploring the existence and potential underpinnings of dog-human and horse-human attachment bonds. Behavioral Processes, 125,114-21.

Perelman, A., Miller, S., Clements, C., Rodriguez, A., Allen, K., \& Cavanaugh, R. (2012). Meditation in a deep south prison: A longitudinal study of the effects of vipassana. Journal of Offender Rehabilitation, 51(3), 176-198. doi:10.1080/10509674.2011.632814.

Pope, C., Lovell, R., \& Brandl, S. (2001). Introductions: Foundations of criminal justice research. In C. Pope, R. Lovell, S. Brandl (Eds.), Voices from the field: Readings in criminal justice research (pp. 1-16). Belmont, CA: Wads-worth.

Ryan, R., \& Deci, E. (2000). Self-determination theory and the facilitation of intrinsic motivation, social development, and well-being. American Psychologist, 55(1), 68-78.

Schinkel, M. (2015) Hook for change or shaky peg? Imprisonment, narratives and desistance. European Journal of Probation, 7(1), pp. 5-20.

Smith, S., \& Ferguson, N. (2005). Getting clean in a drug rehabilitation program in prison: A grounded theory analysis. Journal of Offender Rehabilitation, 42(1), 51-74.

Strauss, A., \& Corbin, J. (1998). Basics of qualitative research: Techniques and procedures for developing grounded theory (2nd ed.). Thousand Oaks, CA: Sage.

Strimple, E. (2003). A history of prison inmate-animal interaction programs. AmericanBehavioral Scientist, 47(1), 70-78.

Sykes, G. (1958). The society of captives. Princeton, NJ: Princeton University Press. 


\section{ARDITTI ET AL.}

Travis, J. (2005). But they all come back: Facing the challenges of prisoner reentry. Washington, DC: Urban Institute Press.

Taylor, S., Bogdan, R., \& DeVault, M. (2016). Introduction to qualitative research methods: A guidebook and resource ( $4^{\text {th }}$ ed.). Hoboken, NJ: John Wiley \& Sons.

Vernick, S., \& Reardon, R. (2001). Career development programs in corrections. Journal of Career Development, 27(4), 265-277.

Virginia Department of Corrections, Statistical Analysis \& Forecast Unit. (2016). State recidivism comparison. Retrieved from http://governor.virginia.gov/media/8167/staterecidivism-comparison-12-16.pdf

Visher, C., Lattimore, P., Barrick, K., \& Tueller, S. (2016). Evaluating the long-term effects of prisoner reentry services on recidivism: What types of services matter? Justice Quarterly, 34(1), 136-165

Wolff, N., Huening, J., Shi, J., \& Frueh, C. (2014). Trauma exposure and posttraumatic stress disorder among incarcerated men. Journal of Urban Health, 91(4), 707-719.

Zilcha-Mano, S., Mikulincer, M., \& Shaver, P. R. (2011). An attachment perspective on humanpet relationships: Conceptualization and assessment of pet attachment orientations. Journal of Research in Personality, 45(4), 345-357.

Joyce A. Arditti is Professor of Human Development and Family Science at Virginia Tech. Her research interests include family disruption, parent-child relationships in vulnerable families, and public policy. She is the author of the book Parental Incarceration and the Family:

Psychological and Social Effects of Imprisonment on Children, Parents, and Caregivers for which she was the 2014 recipient of the Academy of Criminal Justice Sciences Outstanding Book Award. She is a fellow of the National Council on Family Relations and recently was a visiting fellow at the Griffith Criminology Institute in Brisbane, Australia.

Amy A. Morgan is a PhD candidate of Human Development and Family Science: Marriage and Family Therapy at Virginia Tech and a licensed Marriage and Family Therapist. Her research interests include family wellness and resilience, parent-child relationships, and parental incarceration. Amy is heavily involved in policy work, advancing research that explores mental healthcare policy and serving as a statewide legislative policy leader for organizations including AAMFT and the National Council for Behavioral Health.

Sara Spiers is an Educational Advocate and Mentor Coordinator in the Department of Human Development at Washington State University Vancouver. As an educational advocate, she works one-on-one with youth in foster care to develop academic and career goals and help the youth build social supports as they transition from high school or a GED program into a postsecondary program. As a mentor coordinator, she recruits and trains community members to become mentors for youth in foster care. Her research interests include supporting vulnerable populations during major life transitions and public policy. 
Virginia Buechner-Maxwell, is currently a Professor of Large Animal Internal Medicine at Virginia Tech. Her current research interests include exploring the benefit of designing animal friendly spaces in the built environment, documenting the value of animal assisted therapies, and evaluating prison based animal programs in the corrections system of the Commonwealth of Virginia. She is also completing a graduate certificate in Shelter Medicine through the University of Florida in Gainesville.

Victoria A. Shivy is an Associate Professor in the Psychology Department at Virginia Commonwealth University and Licensed Clinical Psychologist (VA \& NY). She studies how people decide on career and educational paths, negotiate the socioemotional and health-related aspects of employment, and re-engage / re-enter work following interruption-- with a particular and longstanding focus on the career-related needs of those who have been imprisoned. She is associate editor of Career Convergence, serves on the editorial boards of a number of scholarly journals, and is active in the Society for Vocational Psychology and the National Career Development Association. 


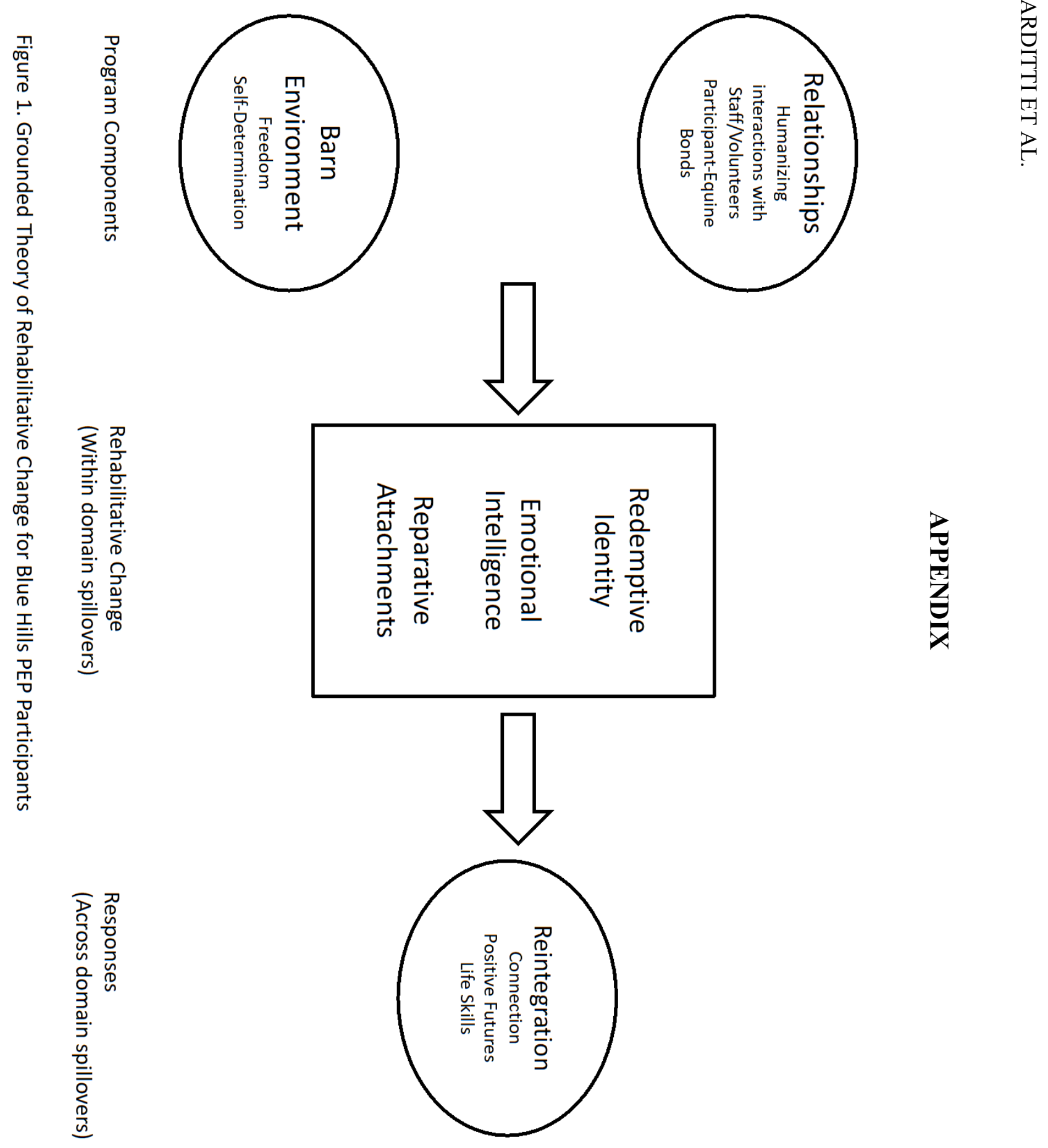

